\title{
Introduction: refugees and innovation
}

\author{
Alexander Betts
}

\begin{abstract}
Doing innovation well presents challenges for how we can work better together as organisations and with displaced people, and how we can break down traditional barriers between actors - all while upholding ethical principles and protection standards relating to displacement.
\end{abstract}

Innovation is not the same thing as invention; it need not involve the creation of something novel but often takes the form of adapting something to a different context. It may be incremental (step by step) or disruptive (breaking the mould). It may relate to change in a product, a process or a paradigm.

And it may involve technology or it may not. The innovation cycle can be thought of as a four-stage process, although the stages do not need to be linear: 1) defining a problem or identifying an opportunity; 2) finding potential solutions; 3 ) testing, adapting and implementing a solution; and 4) appropriate scaling up of the solution.

The term 'innovation' is often poorly understood in humanitarian circles or is viewed sceptically as a buzzword brought in from the private sector. It is often used broadly as an umbrella term to cover the roles of technology, partnership and business. However, more precisely, it can be understood generally as a process for adaptation and improvement.

\section{HIP2014}

In July 2014, the Refugee Studies Centre hosted the Humanitarian Innovation Conference (HIP2014) in Oxford, bringing together over 200 people from the UN, NGOs, governments, community-based organisations, academia and business for two days. Innovation relating to refugees was one of the major themes. This special supplement, generously supported by the Norwegian Ministry of Foreign Affairs, takes stock of some of the themes that emerged at the conference.

At HIP2014, Deputy High Commissioner for Refugees Alexander Aleinikoff offered the definition that innovation represents "dynamic problem solving among friends". ${ }^{1}$
These elements highlight that one of the key components is simply finding ways to enable people to work together - to better connect staff at headquarters to those in the field, to better connect refugees to international organisations, and to link people with problems to people with potential solutions, cutting across traditional sectoral, geographical and socio-economic boundaries.

We know from the literature about innovation that innovation usually comes from crossfertilisation, through nurturing collaborations among people of diverse backgrounds and from different sectors. Such collaborations often emerge from 'ecosystems' - networks of complementary actors. Innovation also relies upon iteration or repetition, and includes a willingness to fail in order to learn and improve. Yet, the global refugee regime is not generally recognised as strong in these areas and has historically been sclerotic and rigid in its human resources structures, procurement processes and professional development opportunities for staff. It is also often highly risk averse, with a fear of failure.

Yet in the humanitarian world more generally, a number of UN organisations and NGOs have been pioneers in drawing upon ideas and language more commonly used by the private sector in order to rethink humanitarian response and gradually integrate innovation as a methodology for change and adaptation. Innovation 'labs', 'challenge grants' and dedicated innovation units have begun to proliferate across the humanitarian system to stimulate new ways of solving problems and adapting to opportunities.

A significant and growing part of the humanitarian innovation debate focuses on 
refugees and displaced populations. This has in part been triggered by the recognition that the majority of the world's refugees are in so-called protracted refugee situations, in which they are often left in closed camps or settlements, indefinitely dependent to varying degrees on humanitarian assistance, without the right to work and with limited freedom of movement. The growing number of humanitarian crises and the changing nature of displacement have further strengthened the need for innovation. Innovation is increasingly seen as an imperative to make responses more effective and sustainable.

\section{Improving organisational responses}

Much of the overall humanitarian

innovation debate has focused on improving organisational response, particularly by drawing in outside ideas and solution-holders.

\section{In 2012, following UNICEF's development} of an innovation unit in-house and innovation labs around the world, UNHCR created 'UNHCR Innovation'; NGOs such as the Norwegian Refugee Council have begun to explore the role of innovation in relation to refugees; universities, including Oxford, Stanford and Southern Methodist University, have developed research on the relationship between refugees and innovation; governments, including the UK's Department for International Development, have provided funding for innovation relating to refugees and displacement; and a growing number of businesses and social entrepreneurs have also begun to enter the refugee innovation space, for a wide array of motives.

UNHCR Innovation, for example, has adopted a core approach of 'Amplify, Connect, Explore' - reflecting the three-fold aspiration to promote internal good practice, better connections in-house, and better partnerships and links to solutions outside the organisation. Much of its early work has used two of the Dollo Ado camps in Ethiopia as a field laboratory for a series of early pilots, and it has created four virtual learning spaces across the thematic areas of Learning, Linking, SelfReliance, and Energy. Among its most notable achievements so far have been the creation of a Refugee Housing Unit in collaboration with the IKEA Foundation, which has been piloted in Iraq and Ethiopia, and the development of 'UNHCR Ideas', an online ideasmanagement platform, connecting field and headquarters staff, developed in collaboration with software company Mindjet/Spigit.

A key part of UNHCR Innovation's work has been reaching out to private sector actors, drawing upon their ideas, funding and networks, and appealing for their involvement on the grounds of a combination of philanthropy, corporate social responsibility and the desire to innovate. Its partners have included the UN Foundation, Hewlett Packard, Ashoka, IDEO, Vodafone, IKEA Foundation and the Hunt Foundation, as well as universities such as Oxford, Stanford and Georgetown.

UNHCR is not alone in seeking to improve organisational response through innovation. Across a range of NGOs there is a growing receptivity to piloting new ideas across and within the health, nutrition, WASH, education and shelter sectors. In food delivery to refugees, for example, WFP is now using cash $^{2}$ as an ever-growing proportion of its aid delivery, and the organisation now sees its role not as emergency food aid but as "ensuring access to nutrients".

\section{Innovation by refugees}

Organisational approaches too often address pre-defined problems using solutions provided by external actors and sometimes neglect the skills, talents and aspirations of crisis-affected communities themselves. In the refugee context, it is important that innovations be responsive to end-users who are best placed to specify problems and to identify solutions that will be relevant to the context of local cultures and markets.

It is also crucial to recognise 'bottom-up' innovation by refugees themselves. When refugees flee across borders, they are faced with new markets, new regulatory environments and new social networks. 
September 2014

They have to adapt by necessity, and so, despite the constraints, they often innovate in their income-generating activities and their adoption of appropriate technologies, for example.

The Humanitarian Innovation Project conducted research with refugees in Uganda to explore their own innovation in respect of their livelihoods, including the ways in which they use technology and engage with the private sector. Based on participatory, mixed-methods research, including a survey of 1,600 refugees in Kampala and two settlements, Nakivale and Kyangwali, we were able to reveal vibrant and complex economic ecosystems that are nationally and transnationally interconnected, and that thrive despite the constraints they face.

In terms of technology, our data showed, for example, that mobile phone and internet use is greater among refugees than in the general population, with $96 \%$ of refugees in urban areas and $71 \%$ in rural settlements having mobile phones, and $51 \%$ and $11 \%$ respectively having access to the internet, often using them for income-generating activities.

Many refugees adapt their own appropriate technologies with a wide array of livelihoods innovations - from Congolese wooden bicycles to sustainable rain-water cooling systems for maize-milling, to video-game parlours based entirely on re-assembled second-hand equipment. One of the two keynote speakers at HIP2014, Ntakamaze Nziyonvira, himself a Congolese refugee in Uganda, described his role in setting up a youth organisation, Ciyota, in the Kyangwali refugee settlement, which has offered educational and entrepreneurial opportunities to young refugees. He also discussed how members of his family and community set up a cooperative to collectively sell sorghum to Nile Breweries, a large beer producer.

These are examples of the need to draw upon ideas from human-centred design and participatory methods to provide an

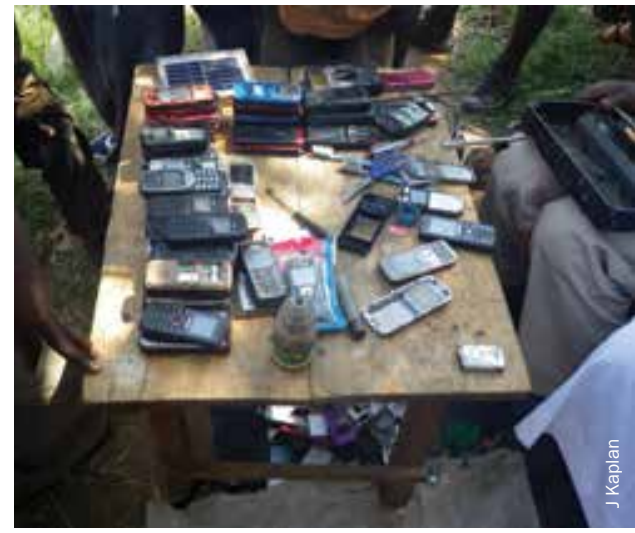

Repairing and selling used phones in Nakivale.

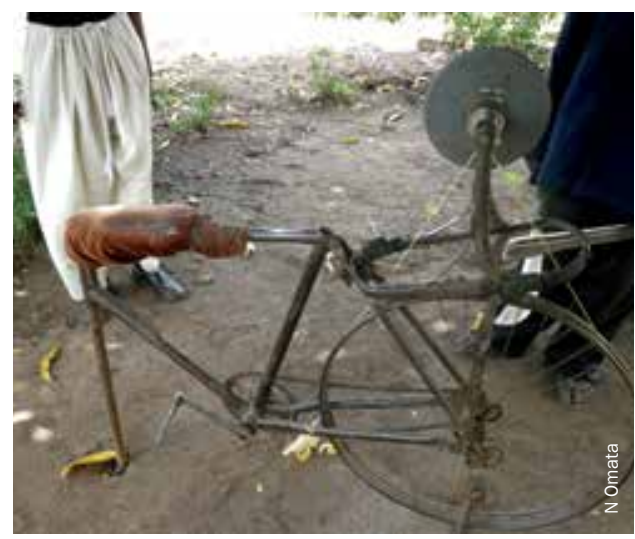

Modified bike for sharpening farm tools in Nakivale.

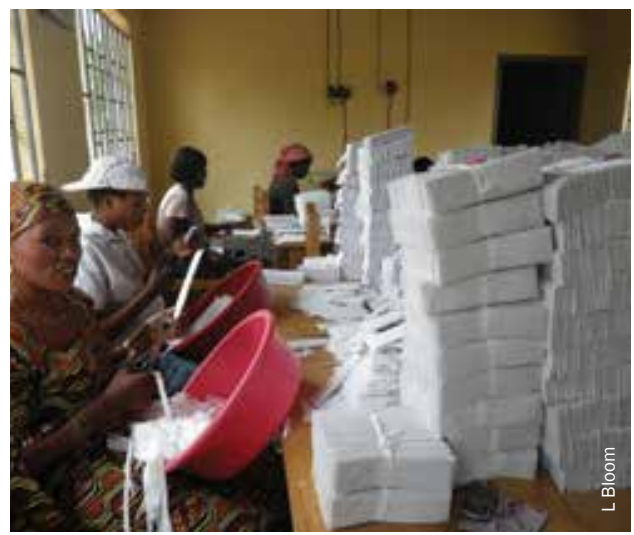

Workers making MakaPads at factory in refugee settlement. See article on page 14 . 
alternative model of bottom-up innovation that builds on the capacities of displaced populations. This model requires an approach that recognises and understands the capacity for innovation within communities and also puts these communities and local systems at the heart of the innovation process, regardless of where key ideas or resources originate.

\section{Metrics and standards}

One of the crucial observations of HIP2014 was that "there can be no innovation without evidence"; unless we can measure the impact of pilots and have metrics - standards for measurement - for what success or failure mean, then attempts to innovate are likely to be dead-ends, and potentially even harmful. Yet we have few good metrics for innovation, and monitoring and evaluation standards in the area remain underdeveloped.

In the refugee context, one of the principal aspirations for innovation is that it can contribute towards refugees' self-reliance. But we lack accepted metrics for self-reliance or, more broadly, for what UNHCR is now calling 'progressive solutions', the gradual move from some degree of dependence on humanitarian assistance and protection towards greater autonomy and reintegration within the state system. So by what standards, and on whose behalf, should we judge a refugee innovation?

Here there is a crucial role for research in general and for universities in particular. Any refugee innovation project should build into its programming a research component that can establish metrics and baseline data in order to measure the impact of a pilot or prototype against clearly defined criteria. This also requires broader research to establish standards and metrics for the normative goals of the refugee regime - including empowerment, protection and sustainability of solutions - which are currently lacking.

It is also important that ethical and normative standards for refugee innovation should be developed. As the range of actors engaging in refugee assistance broadens, so UNHCR's role as the central guardian or gatekeeper in the refugee regime will change. A range of non-traditional actors will interact with the refugee regime for an array of complex motives. Businesses, for example, are diverse and come in many forms. While it will be difficult to exclude particular actors, ethical standards and codes of conduct will have a central role to play in outlining the requirements for an actor to be regarded as legitimate in its engagement with innovation in the refugee context.

The humanitarian innovation debate represents an opportunity to re-think key aspects of how we do refugee assistance. Many of the challenges of refugee protection and solutions are longstanding. However, many of the currently applied 'solutions' are not fit for purpose, encouraging dependency rather than facilitating sustainable opportunities.

HIP2014 brought together many of the key stakeholders in this debate. It exemplified the value of dialogue and debate across sectors, connecting people who might not otherwise speak to one another. It led to new ideas and new networks. It engaged international organisations, NGOs, community-based organisations, governments, universities, researchers and, crucially, refugees themselves in a shared conversation. The challenge, however, is to transform dialogue into action and to find ways to - collectively - learn better and pilot better approaches. This requires conceptual and moral clarity. There are immense opportunities, especially if the skills, talents and aspirations of displaced populations themselves are at the heart of the conversation.

Alexander Betts alexander.betts@qeh.ox.ac.uk is Associate Professor in Refugee and Forced Migration Studies at the Refugee Studies Centre, University of Oxford. www.rsc.ox.ac.uk He is the Director of the Humanitarian Innovation Project www.oxhip.org and will be Director of the Refugee Studies Centre from October 2014.

1. See article by Alexander Aleinikoff on pages 8-10.

2. See article by Erik Abild on pages 23-5. 